\title{
Finite Element Modeling Based on Composite Damage Theory for the Strength Prediction of 3D Braided Composites Structures
}

\author{
Long Hu, Zhenguo Liu, Yibo Wang, Jiajun Ou, Dongxu Liu \\ School of Aeronautic Science and Engineering \\ Beihang University(BUAA) \\ Beijing, China \\ e-mail: liuzg@buaa.edu.cn
}

\begin{abstract}
Finite element analysis for the strength prediction of 3D braided composites structures are presented in this paper. A strength analysis model was established to investigate the strength characteristics of the $3 \mathrm{D}$ braided composites. Repeated unit-cell (RUC) model was used in this model to describe the microstructure of 3D braided composites and differences between yarn configurations in corner, surface and interior RUCs were considered. Composite damage model were introduced into the yarns of the RUCs in the analysis model and the macroscopic failure and damage evolution of the 3D braided composites structures were characterized by the damage of yarns by nonlinear homogenization method. To validate the veracity of this model, a user defined material subroutine (UMAT) was developed to introduce this model into the finite element analysis software and the damage progression of a 3D braided composite structure under three-point bending was simulated. Good agreements were achieved in the loaddeflection curves and damage morphology between experimental and numerical results.
\end{abstract}

Keywords-3D braided composites; strength prediction; composite damage theory; repeated unit cell; strength analysis model

\section{INTRODUCTION}

3D braided composites have been widely used in advanced structures in aeronautic and astronautic industries with their outstanding mechanical properties. Compared with the conventional laminated composites, 3D braided composites overcome the delamination problem and provide a high multi-directional loading capacity and favorable impact and fatigue resistance. Over the last few decades, extensive experimental investigation and theoretical analyses of 3D braided composites have been conducted and great achievements were obtained.

Investigations on the elastic properties of $3 \mathrm{D}$ braided composites [1-4] have shown good agreement between predicted results and experiment data. For the strength prediction, Tang and Postle [5] derived a nonlinear finite element approach for simulating the deformation of $3 \mathrm{D}$ braided composites. Zeng et al. [6] presented a damage model for 3D braided composites with transverse cracking and analyzed the stress field and tensile strength of 3D braided composites by using a simplified geometrical model. Fang et al. [7, 8] introduced previously developed continuum damage mechanics based model to simulate mesoscopic damage behavior of 3D braided composites under unidirectional tension and compression and the effect of yarn distortion was considered in the simulation. Dong et al. [9] simulated the non-linear behavior of cumulative damages of $3 \mathrm{D}$ braided composites by the method of Asymptotic Expansion Homogenization (AEH) and the influence of face cell and corner cell and proper boundary conditions on each kind of unit cells were studied in his paper.

Most of the investigations on the elastic and strength properties of 3D braided composite were based on simple loading modes such as unidirectional tension and compression, in which no macroscopic model needs to be built and the mechanical properties of 3D braided composites can be characterized by the repeated unit cell, providing a way to consider the effect of microstructure details on the macro-scale property predictions. However, this method is not suitable for investigating the macroscopic strength properties of 3D braided composites structures as the stress distribution inside the braided composite structures may be non-uniform and cannot be characterized by a single unit cell.

A strength analysis model based on the RUCs was established in this paper. The repeated unit-cell (RUC) model was used to simulate the mechanical properties of 3D braided composites and three kinds of RUCs were considered based on the different yarn configurations in the corner, surface and interior regions of braided composites. Three-dimensional composite damage models were applied for the yarns in RUCs to simulate the macroscopic nonlinear response of braided composites. A user defined material subroutine (UMAT) was developed to introduce this method into the numerical simulation. The strength analysis of a 3D braided composite structure was made to verify the validate of the model and good agreements were obtained between numerical prediction and experimental results.

\section{STRENGTH ANALYSIS MODEL}

\section{A. Repeated unit-cell model}

A repeated unit-cell model of 3D full five directional (3DF5D) braided composites which was provided by Zhang and Liu [10] is used in this paper. According to the model, the $3 \mathrm{D}$ full 5 directional braided composites are comprised of two kinds of yarns :axial yarns and braiding yarns and the braided structure is divided into three kinds of RUCs, interior RUC, surface RUC and corner RUC as shown in Fig .1. 
According to the geometrical relationship in RUCs, the interior braiding angle $\gamma$, surface braiding angle $\beta$ and corner braiding angle $\theta$ can be deduced from the following equation:

$$
\begin{gathered}
\tan \gamma=\frac{\tan \alpha}{\sin \varphi} \\
\tan \beta=\frac{\tan \alpha}{2} \\
\tan \theta=\frac{\sqrt{\left(W_{\mathrm{e}}\right)^{2}+\left(T_{\mathrm{e}}\right)^{2}}}{\frac{3}{4} h}
\end{gathered}
$$

Where $\alpha$ is the braiding angle between the trend of braiding yarn axis on the preform surface and the braiding direction. $W_{\mathrm{e}}$ and $T_{\mathrm{e}}$ are the width and thickness of the corner RUC. $\alpha$ and $\varphi$ are used as control parameters and can be measured. Thus other angles can be confirmed.

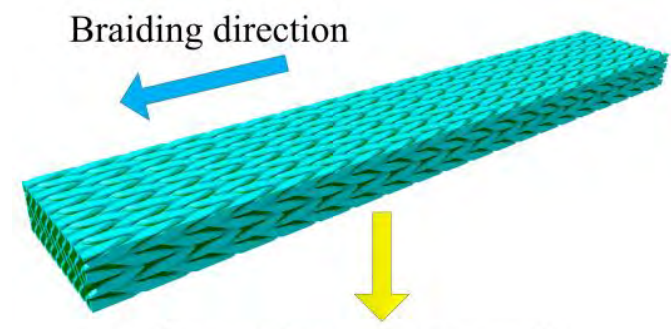

Surface region Corner region

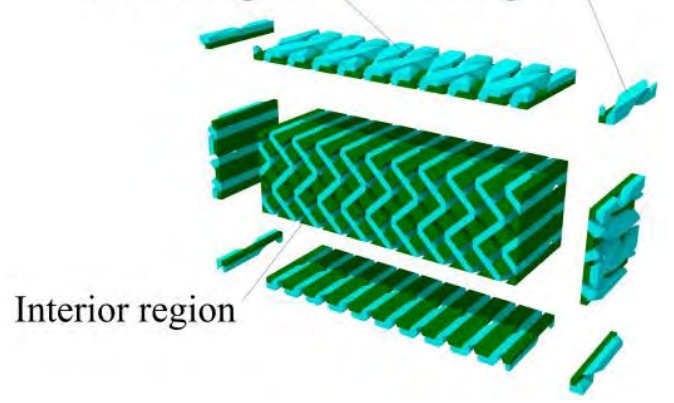

Figure 1. Braided structure and RUC region division of 3DF5D braided composites.

\section{B. Composite damage model of yarns}

\section{1) Damage Initiation Criterion}

The yarns are regarded as unidirectional composite and the resin is regard as isotropic materials. 3D Hashin failure criterion [11] is used to define damage initiation of the yarns, which categorizes the failure mechanisms into two modes: yarn longitudinal (L direction as shown in Fig .2) failure and yarn transverse ( $\mathrm{T}$ and $\mathrm{Z}$ direction as shown in Fig .2) failure.

In order to account for tensile and compressive failure in yarn longitudinal direction, two failure criterions are given in the following form.

Longitudinal tensile failure criterion is expressed as:

$$
f_{\mathrm{Lt}}=\left(\frac{\sigma_{\mathrm{L}}}{X_{\mathrm{L}}^{\mathrm{t}}}\right)^{2}+\alpha\left(\frac{\sigma_{\mathrm{LT}}}{S_{\mathrm{LT}}}\right)^{2}+\alpha\left(\frac{\sigma_{\mathrm{ZT}}}{S_{\mathrm{ZT}}}\right)^{2}=1, \quad \sigma_{\mathrm{L}} \geq 0
$$

Longitudinal compressive failure is expressed as:

$$
f_{\mathrm{Lc}}=\left(\frac{\sigma_{\mathrm{L}}}{X_{\mathrm{L}}^{\mathrm{c}}}\right)^{2}=1, \quad \sigma_{\mathrm{L}}<0
$$

The tensile and compressive failure are also considered in transverse failure criterion.

Transverse tensile and shear failure:

$$
\begin{aligned}
f_{\mathrm{T}(\mathrm{Z}) \mathrm{t}}= & \left(\frac{\sigma_{\mathrm{T}}+\sigma_{\mathrm{Z}}}{X_{\mathrm{T}}^{\mathrm{t}}}\right)^{2}+\frac{\sigma_{\mathrm{TZ}}^{2}-\sigma_{\mathrm{T}} \sigma_{\mathrm{Z}}}{\left(S_{\mathrm{TZ}}\right)^{2}} \\
& +\left(\frac{\sigma_{\mathrm{LT}}}{S_{\mathrm{LT}}}\right)^{2}+\left(\frac{\sigma_{\mathrm{ZT}}}{S_{\mathrm{ZT}}}\right)^{2}=1, \quad \sigma_{\mathrm{T}}+\sigma_{\mathrm{Z}} \geq 0
\end{aligned}
$$

Transverse compressive and shear failure:

$$
\begin{aligned}
f_{\mathrm{T}(\mathrm{Z}) \mathrm{c}}= & \frac{1}{X_{\mathrm{T}}^{\mathrm{c}}}\left[\left(\frac{X_{\mathrm{T}}^{\mathrm{c}}}{2 S_{\mathrm{TZ}}}\right)^{2}-1\right]\left(\sigma_{\mathrm{T}}+\sigma_{\mathrm{Z}}\right) \\
& +\left(\frac{\sigma_{\mathrm{T}}+\sigma_{\mathrm{Z}}}{2 S_{\mathrm{TZ}}}\right)^{2}+\frac{\left(\sigma_{\mathrm{TZ}}^{2}-\sigma_{\mathrm{T}} \sigma_{\mathrm{Z}}\right)}{\left(S_{\mathrm{TZ}}\right)^{2}} \\
& +\left(\frac{\sigma_{\mathrm{LT}}}{S_{\mathrm{LT}}}\right)^{2}+\left(\frac{\sigma_{\mathrm{LZ}}}{S_{\mathrm{LZ}}}\right)^{2}=1, \sigma_{\mathrm{T}}+\sigma_{\mathrm{Z}}<0
\end{aligned}
$$

In the above equations, $X_{\mathrm{L}}^{\mathrm{t}}, X_{\mathrm{T}}^{\mathrm{t}}$ are tensile strengths in the longitudinal and transverse direction of yarn. $X_{\mathrm{L}}^{\mathrm{c}}$, $X_{\mathrm{T}}^{\mathrm{c}}$ are compressive strengths in the longitudinal and transverse direction of yarn. $S_{\mathrm{LT}}, S_{\mathrm{LZ}}$ and $S_{\mathrm{ZT}}$ are LT, TZ and ZL shear strengths. $\alpha$ is the contribution factor in the failure modes.

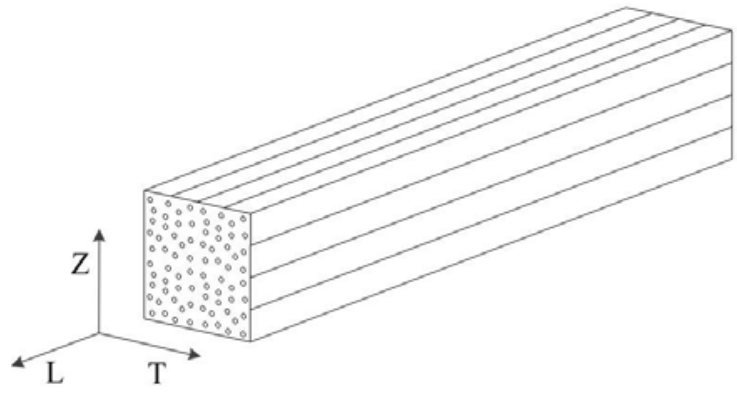

Figure 2. Local material directions of yarn.

\section{2) Damage evolution model}

The template is used to format your paper and style the text. All margins, column widths, line spaces, and text fonts are prescribed; please do not alter them. You may note peculiarities. For example, the head margin in this template measures proportionately more than is customary. This measurement and others are deliberate, using specifications that anticipate your paper as one part of the entire proceedings, and not as an independent document. Please do not revise any of the current designations.

Three damage variables $D_{i}(i=\mathrm{L}, \mathrm{T}, \mathrm{Z})$ are involved to define damage evolution of the yarn at $\mathrm{L}, \mathrm{T}$ and $\mathrm{Z}$ direction. The damage variables are governed by the critical damage areas $A_{i}(i=\mathrm{L}, \mathrm{T}, \mathrm{Z})$ and evolved from 0 to 1 irreversibly after failure initiation. The relationship between damage variables and critical damage areas can be defined as:

$$
D_{i}=\frac{A_{i}}{A_{0}}
$$

Where $A_{0}$ is the critical area of the yarns before damage initiation and the crack band theory established by 
Bažant [12], the energy released through the damage evolution is equal to the strain energy of the damage district:

$$
\frac{1}{2} \sigma_{i} \varepsilon_{i} A_{0} l_{0}=G_{i} A_{i}
$$

Where $\sigma_{i}, \varepsilon_{i}, G_{i}$ is the equivalent strain, equivalent stress and fracture energy density of failure mode $i$ $(i=\mathrm{L}, \mathrm{T}, \mathrm{Z}) . l_{0}$ is the characteristic length of damage district. So the damage variables can be defined as:

$$
D_{i}=\frac{A_{i}}{A_{0}}=\frac{\sigma_{i} \varepsilon_{i} l_{0}}{2 G_{i}}
$$

During the damage evolution, the flexibility matrix of the yarns is related to the damage variables and can be expressed as:

$$
\boldsymbol{S}(\boldsymbol{D})=\left[\begin{array}{cccccc}
\frac{1}{b_{\mathrm{L}} E_{11}} & -\frac{v_{12}}{E_{11}} & -\frac{v_{13}}{E_{11}} & 0 & 0 & 0 \\
\frac{1}{b_{\mathrm{T}} E_{22}} & -\frac{v_{23}}{E_{22}} & 0 & 0 & 0 \\
& \frac{1}{b_{\mathrm{Z}} E_{33}} & 0 & 0 & 0 \\
& \frac{1}{b_{\mathrm{LT}} G_{12}} & 0 & 0 \\
& & & \frac{1}{b_{\mathrm{LZ}} G_{13}} & 0 \\
\text { symm } & & & & \frac{1}{b_{\mathrm{LZ}} G_{23}}
\end{array}\right]
$$

Where parameter $b_{i}$ is defined as:

$$
\begin{gathered}
b_{\mathrm{L}}=1-D_{\mathrm{L}}, b_{\mathrm{T}}=1-D_{\mathrm{T}}, b_{\mathrm{Z}}=1-D_{\mathrm{Z}} \\
b_{\mathrm{LT}}=\left(1-D_{\mathrm{L}}\right)\left(1-D_{\mathrm{T}}\right) \\
b_{\mathrm{LZ}}=\left(1-D_{\mathrm{L}}\right)\left(1-D_{\mathrm{Z}}\right) \\
b_{\mathrm{TZ}}=\left(1-D_{\mathrm{T}}\right)\left(1-D_{\mathrm{Z}}\right)
\end{gathered}
$$

The damaged stiffness matrix $\boldsymbol{C}(\boldsymbol{D})$ can be defined as the inverse of the $S(D)$ :

$$
C(D)=S^{-1}(D)
$$

\section{Nonlinear homogenization method}

The total stiffness matrix of RUCs can be calculated by the volume averaging method with the stiffness matrix of yarns and resin:

$$
\overline{\boldsymbol{C}}_{\text {total }}=\sum_{n=1}^{k} V_{n} \overline{\boldsymbol{C}}_{n}
$$

Where $\overline{\boldsymbol{C}}_{\text {total }}$ is the total stiffness matrix of RUC. $V_{n}$ is the volume fraction and of the yarns and resin. $\overline{\boldsymbol{C}}_{n}$ is the stiffness matrix of the yarns and resin at the global coordinate system and can be expressed as:

$$
\overline{\boldsymbol{C}}_{n}=\boldsymbol{T}_{\sigma, n}: \boldsymbol{C}_{n}: \boldsymbol{T}_{\sigma, n}^{\mathrm{T}}
$$

In which $\boldsymbol{C}_{n}$ is the stiffness matrix of the yarns and resin at their local material coordinate systems. $\boldsymbol{T}_{\sigma, n}$ is the transformation matrix of stress vector and $\boldsymbol{T}_{\sigma, n}^{\mathrm{T}}$ is the transpose of $\boldsymbol{T}_{\sigma, n} . \boldsymbol{T}_{\sigma, n}$ is presented as:

$$
\begin{aligned}
& \boldsymbol{T}_{\sigma}= \\
& {\left[\begin{array}{cccccc}
l_{1}^{2} & m_{1}^{2} & n_{1}^{2} & 2 m_{1} n_{1} & 2 n_{1} l_{1} & 2 l_{1} m_{1} \\
l_{2}^{2} & m_{2}^{2} & n_{2}^{2} & 2 m_{2} n_{2} & 2 n_{2} l_{2} & 2 l_{2} m_{2} \\
l_{3}^{2} & m_{3}^{2} & n_{3}^{2} & 2 m_{3} n_{3} & 2 n_{3} l_{3} & 2 l_{3} m_{3} \\
l_{1} l_{2} & m_{1} m_{2} & n_{1} n_{2} & m_{1} n_{2}+m_{2} n_{1} & n_{1} l_{2}+n_{2} l_{1} & l_{1} m_{2}+l_{2} m_{1} \\
l_{1} l_{3} & m_{1} m_{3} & n_{1} n_{3} & m_{1} n_{3}+m_{3} n_{1} & n_{1} l_{3}+n_{3} l_{1} & l_{1} m_{3}+l_{3} m_{1} \\
l_{2} l_{3} & m_{2} m_{3} & n_{2} n_{3} & m_{2} n_{3}+m_{3} n_{2} & n_{2} l_{3}+n_{3} l_{2} & l_{2} m_{3}+l_{3} m_{2}
\end{array}\right]}
\end{aligned}
$$

Where $l_{i}, m_{i}, n_{i}$ are the cosines between local material coordinate axes of the components and global coordinate axes of RUC.

As the strength property of braided composite is controlled by the mechanical behaviors of the yarns and resin, continuum damage models are applied to these components to simulate the progressive failure of the braided composite structures. During the simulation, $\boldsymbol{C}_{n}$ is the elastic stiffness matrix of the yarns and resin before initial damage occurs. When the stress level of one yarn or resin reaches the damage initiation criteria, $\boldsymbol{C}_{n}$ of this yarn or resin will turn into the damaged stiffness matrix $\boldsymbol{C}(\boldsymbol{D})_{n}$. The damage initiation and evolution in the yarns and resin are related to their stress state. Therefore, the local stress of these components should be calculated at each increment step of the simulation.

\section{NUMERICAL EXAMPLE}

To validate the veracity of the strength analysis model prescribed in the previous sections, a finite element model of a 3D full five directional (3DF5D) braided composite structure under three-point bending is built. The experimental results have been provided by Huang[13].

Finite element software package ABAQUS/Standard is used for the finite element modeling and calculation. The geometrical model, contact property, boundary condition and load step are modeled and settled in ABAQUS/CAE and the mechanical properties of fiber and matrix are given and listed in TABLE I .

The distribution of interior RUC, surface RUC and corner RUC are considered in the model as shown in Fig .3. A user defined material subroutine (UMAT) is developed to introduce the strength analysis method mentioned above into the simulation. The meshing scheme of the model is shown in Fig .4. Eight-node reduced integration element with hourglass control (C3D8R) and four node bilinear rigid quadrilateral element (R3D4) are implemented for mesh discretization of the 3D braided composite specimen and rollers.

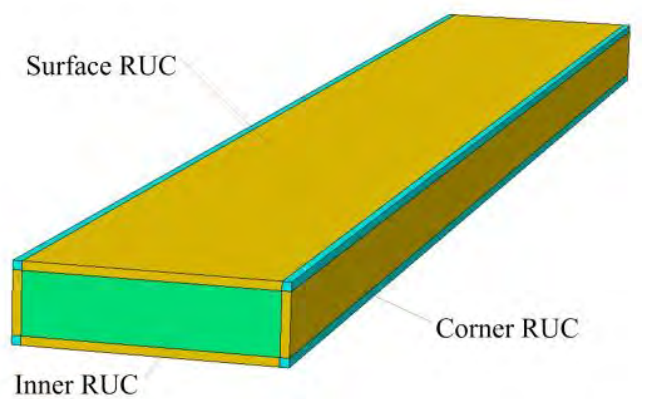

Figure 3. Local material directions of yarn. 


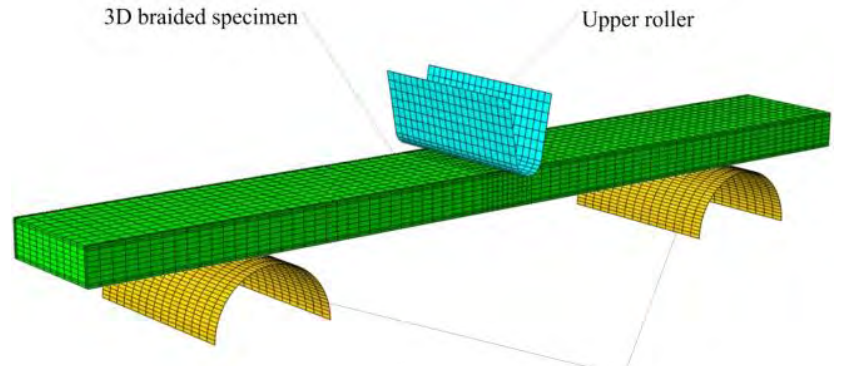

Supporting roller

Figure 4. Meshing schemes of specimen and rollers under three-point bending.

TABLE I. MECHANICAL PROPERTIES OF FIBER AND RESIN

\begin{tabular}{|c|c|c|}
\hline & carbon fiber & resin \\
\hline Longitudinal tensile modulus $E_{11}$ & $230 \mathrm{GPa}$ & $3.5 \mathrm{GPa}$ \\
\hline Longitudinal compressive modulus $E_{11}$ & $180 \mathrm{GPa}$ & - \\
\hline Transverse modulus $E_{22}$ & $40 \mathrm{GPa}$ & - \\
\hline Poisson's ratio $v_{12}$ & 0.26 & 0.35 \\
\hline Shear modulus $G_{12}$ & $24 \mathrm{GPa}$ & - \\
\hline Shear modulus $G_{23}$ & $14.3 \mathrm{GPa}$ & - \\
\hline Tensile strength $X^{\mathrm{t}}$ & $4900 \mathrm{MPa}$ & $80 \mathrm{MPa}$ \\
\hline Compressive strength $X^{\mathrm{c}}$ & $2470 \mathrm{MPa}$ & $241 \mathrm{MPa}$ \\
\hline Shear strength $S$ & - & $60 \mathrm{MPa}$ \\
\hline
\end{tabular}

\section{RESULTS AND DISCUSSIONS}

The predicted load-deflection curves of the 3DF5D braided composite structure under three point bending in comparison with the experimental results are given in Fig .5. The maximum loads of $3 \mathrm{D}$ braided composite structure on the experimental results is $3305 \mathrm{~N}$ while that of the numerical prediction is $3436 \mathrm{~N}$. It can be seen that good agreements are obtained in both linear and nonlinear stages between numerical prediction and experimental results and the calculation errors of predicted maximum loads are within an acceptable range.

According to the damage model provided in previous sections, each yarn in the RUCs has three damage variables for the $\mathrm{L}, \mathrm{T}$ and $\mathrm{Z}$ direction, so the RUC model gets up to fifteen principal damage values together. The maximum of these damage values is taken as the representation of overall damage level.

The overall damage evolution in different RUCs the 3DF5D braided composite structure during numerical simulation are shown in Fig .6. It can be seen that most of the damages appear in the middle of the specimens. The damage areas in surface RUC region and corner RUC region much bigger than that in interior RUC region as tensile and compressive stress concentrate on the top and bottom surfaces where the upper roller contacts under three-point bending loading. More damages are observed on the top zone than the bottom zone in all of the three
RUC regions, demonstrating that the 3DF5D braided composites have higher tensile strength than compressive strength.

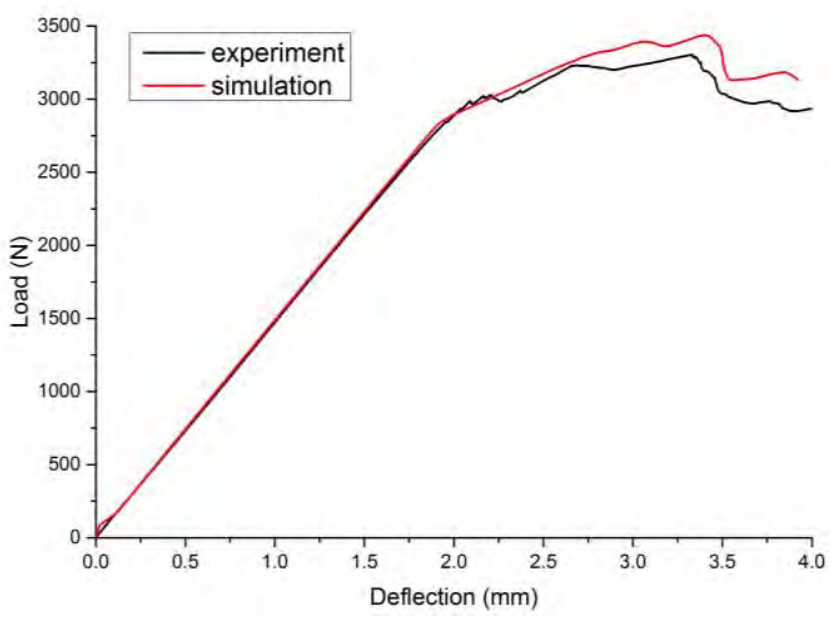

Figure 5. Predicted and experimental Load-Deflection curves of 3D braided composite structure.
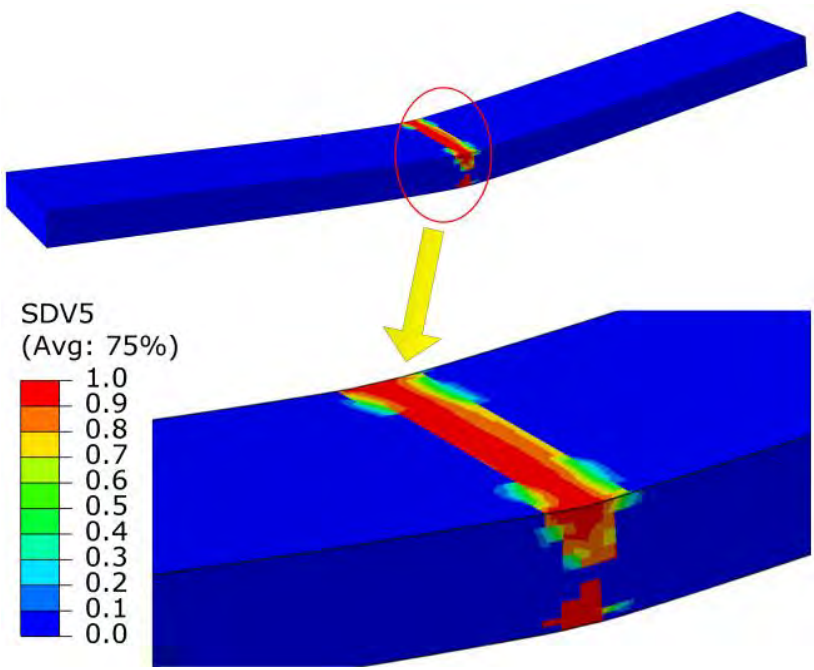

Figure 6. Overall damage morphology in the 3DF5D braided composite structure.

\section{CONCLUSIONS}

A strength analysis model is formulated and implemented into the FE code ABAQUS/Standard for the strength prediction of 3D braided composites sturcutres in this paper. Only macroscopic model should be built though this method and the macro-mechanical properties of $3 \mathrm{D}$ braided composites can be predicted according to the microstructure and mechanical properties of yarns. A repeated unit-cell model provided by the former researchers is introduced to describe the microstructure of 3DF5D braided composites, which identify three kinds of RUCs in the preform corner, surface and interior regions according to the yarn configuration. Composite damage models are applied to the yarns to simulate the nonlinear response and damage characteristics of 3DF5D braided composites. A numerical example is made to verify the validity of the strength analysis model. The simulation results are analyzed and compared with the experimental results provided by former researchers and good agreement is obtained. The strength analysis model provided in this 
paper can be useful for the further research on the 3D braided composites structures.

\section{ACKNOWLEDGMENT}

This work is supported by the Blue Sky Rookie Foundation of Beihang University (YWF-13-T-RSC-071).

\section{REFERENCES}

[1] Sun H Y, Qiao X, "Prediction of the mechanical properties of three-dimensionally braided composites," Compos Sci Technol, vol. 57(6), 1997, pp. 623-629.

[2] Tang Z X, Postle R., "Mechanics of three-dimensional braided structures for composite materials-Part II: prediction of the elastic moduli,". Compos Struct, vol. 51(4), 2001, pp. 451-457.

[3] Xu K, Xu X W, "Finite element analysis of mechanical properties of 3D five-directional braided composites," Mat Sci Eng A-Struct, vol. 487(1), 2008, pp. 499-509.

[4] Jiang L, Zeng T, Yan S, et al, "Theoretical prediction on the mechanical properties of $3 \mathrm{D}$ braided composites using a helix geometry model," Compos Struct, vol. 100, 2013, pp. 511-516.

[5] Tang Z X, Postle R, "Mechanics of three-dimensional braided structures for composite materials-part III: nonlinear finite element deformation analysis," Compos Struct, vol. 55(3), 2002, pp. 307317.
[6] Zeng T, Wu L, Guo L, "A damage model for 3D braided composites with transverse cracking," Compos Struct, vol. 62(2), 2003, pp. 163-170.

[7] Guo-dong F, Jun L, Bao-lai W, "Progressive damage and nonlinear analysis of 3D four-directional braided composites under unidirectional tension," Compos Struct, vol. 89(1), 2009, pp. 126133.

[8] Fang G, Liang J, Lu Q, et al, "Investigation on the compressive properties of the three dimensional four-directional braided composites," Compos Struct, vol. 93(2), 2011, pp. 392-405.

[9] Dong J, Feng M, "Asymptotic expansion homogenization for simulating progressive damage of 3D braided composites," Compos Struct, vol. 92(4), 2010, pp. 873-882.

[10] F. Zhang, Z.G. Liu, Z. Wu, et al, "A New Scheme and Microstructural Model for 3D Full 5-directional Braided Composites," Chinese J Aeronaut, vol. 23(1), 2010, pp. 61-67.

[11] Hashin, Zvi, "Failure criteria for unidirectional fiber composites," J Appl Mech, vol. 47(2), 1980, pp. 329-334.

[12] Bažant Z P, Oh B H, "Crack band theory for fracture of concrete," Matériaux et construction, vol. 16(3), 1983, pp. 155-177.

[13] Y.N. Huang, Research on the Mechanical Properties of Three Dimensional Braided Composites, Master Thesis, Beihang University, 2012 [in Chinese]. 